\title{
Sickle Cell Retinopathy (SCR) in a Patient with Sickle Cell Trait - A Rare Case Report
}

\author{
Vandana Panjwani ${ }^{1}$, Sachin Daigavane ${ }^{2}$, Sourya Acharya ${ }^{3}$, Madhumita Prasad $^{4}$ \\ ${ }^{1}$ Department of Ophthalmology, Datta Meghe Institute of Medical Sciences (Deemed to Be University), J.N. Medical \\ College, Sawangi (M), Wardha, Maharashtra, India. ${ }^{2}$ Department of Ophthalmology, Datta Meghe Institute of Medical \\ Sciences (Deemed to Be University), J.N. Medical College, Sawangi (M), Wardha, Maharashtra, India. ${ }^{3}$ Department of \\ Medicine, Datta Meghe Institute of Medical Sciences (Deemed to Be University), J.N. Medical College, Sawangi (M), \\ Wardha, Maharashtra, India. ${ }^{4}$ Department of Ophthalmology, Datta Meghe Institute of Medical Sciences (Deemed to \\ Be University), J.N. Medical College, Sawangi (M), Wardha, Maharashtra, India.
}

\section{INTRODUCTION}

Sickle cell trait is an inherited hematologic anomaly that affects 1 million to 3 million Americans and 8 to 10 percent of African Americans. It also affects other races like Hispanics, south Asians, Caucasians from southern Europe, and people from Middle Eastern countries. Evidence based estimations suggests that more than 100 million people worldwide have sickle cell trait. Unlike sickle cell disease, where two genes that cause the production of abnormal haemoglobin, individuals with sickle cell trait carry only one defective gene and typically live normal lives. Extreme conditions such as severe dehydration and high-intensity physical activity can lead to serious health issues, including sudden death, for individuals with sickle cell trait. We present a case of a young female with sickle cell trait who presented with overt retinopathy which is a rare phenomenon.

Sickle cell disease is a broad gamut of disorders resulting due to the presence of defective oxygen carrying iron pigment in the blood. This abnormal haemoglobin most commonly results from the mutation of glutamic acid to valine at the $6^{\text {th }}$ position of the beta globin chain. The stretch of the syndrome includes sickle cell disease, sickle cell trait, sickle cell thalassaemia. The patients with sickle cell disease are prone to develop vaso-occlusive crises leading to micro angiopathic complications like nephropathy and retinopathy. Sickle cell retinopathy most commonly occur in $\mathrm{HbC}$ disease and very rare in sickle cell trait (AS).[1]

Most cases with sickle cell trait usually do not present with overt symptoms ophthalmogically or otherwise. Occasionally they can have hematuria. But under extreme situations like high altitude, severe dehydration, or intensely high physical activity, red cells can become sickled. Then these subjects may develop complications like rhabdomyolysis, micro infarcts in spleen.

In India SCD was first described in the Nilgiri Hills of northern Tamil Nadu. The sickle cell gene is now known to be widespread in the Deccan plateau of central India, north of Kerala and Tamil Nadu. Anthropological Survey of India have documented the distribution and frequency of the sickle cell trait to be as high as 35 per cent in some communities. $[2,3]$

\author{
Corresponding Author: \\ Dr. Sourya Acharya, \\ Professor, \\ Department of Medicine, \\ Datta Meghe Institute of Medical \\ Sciences (Deemed to be University), \\ J.N. Medical College, Sawangi (M), \\ Wardha, Maharashtra, India. \\ E-mail: souryaacharya74@gmail.com
}

DOI: $10.14260 / \mathrm{jemds} / 2020 / 439$

How to Cite This Article:

Panjwani V, Daigavane S, Acharya S, et al. Sickle cell retinopathy (SCR) in a patient with sickle cell trait - a rare case report. J. Evolution Med. Dent. Sci. 2020;9(28): 20162018, DOI: 10.14260/jemds/2020/439

Submission 19-03-2020,

Peer Review 05-06-2020,

Acceptance 11-06-2020,

Published 13-07-2020.

Copyright (C) 2020 JEMDS. This is an open access article distributed under Creative Commons Attribution License [Attribution 4.0 International (CC BY 4.0)] 


\section{PRESENTATION OF CASE}

A 28-year-old young female was referred to the department of ophthalmology from medicine with complaints of diminution and blurring of vision in both the eyes since 4 days which was progressive and painless in nature. Right eye and left eye examination revealed visual acuity of $6 / 24$ improving to $6 / 12$ by pinhole in right eye and visual acuity of $1 / 6$ in the left eye. Comma shaped prominent blood channels in the bulbar conjunctiva and few atrophic patches in the substance of iris were present in both the eyes. Rest of the anterior segment was within normal limits and intraocular pressure (measured by non-contact tonometer) was recorded to be $13 \mathrm{~mm} \mathrm{Hg}$ and $14 \mathrm{~mm} \mathrm{Hg}$ in right and left eye respectively.

Posterior segment evaluation of right eye revealed tortuosity of blood vessels in all quadrants and background revealed multiple splinter haemorrhages temporal to disc, 2 boat shaped subhyaloid haemorrhages in the inferotemporal and superotemporal quadrant, superficial intraretinal haemorrhage suggestive of salmon patch in the superotemporal quadrant and retinal thickening was noted in the macular area. [Fig. 1]

Posterior segment evaluation of left eye also revealed tortuosity of vessels and multiple blot haemorrhages in the temporal quadrant and a large subhyaloid bleed involving the temporal and inferior quadrant including the macular area along with oedematous macular area. [Fig. 2]

We decided to wait and watch for this patient as there was no evidence of proliferative disease at the time of presentation. After 2 weeks of observation we noticed that splinter haemorrhages and subhyaloid haemorrhages of right eye were resolved although the salmon patch haemorrhage didn't resolve completely but the macular oedema had subsided [Fig. 2]. While in the left eye the subhyaloid bleed had reduced markedly and so did the macular oedema with improvement of visual acuity to 6/60. [Fig. 4]

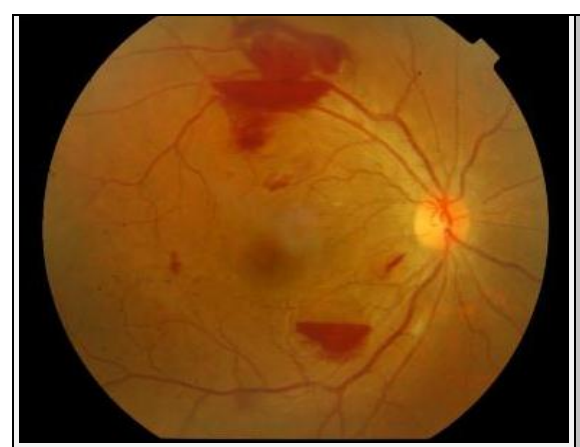

Figure 1. Right Eye: $1^{\text {st }}$ Presentation

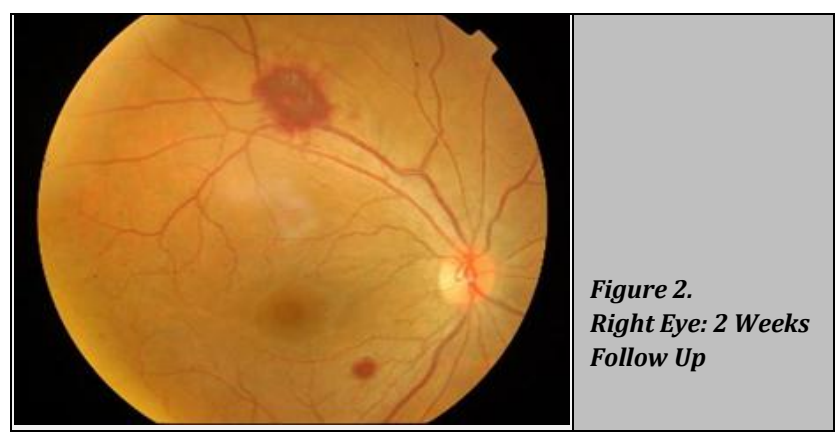

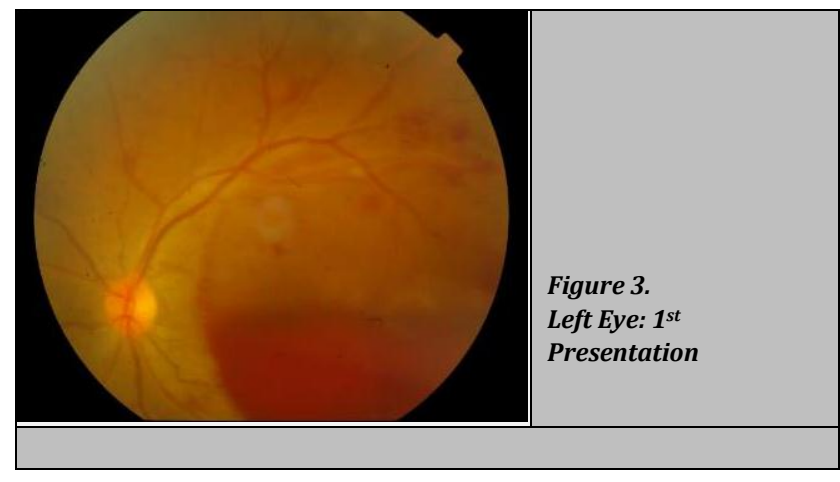

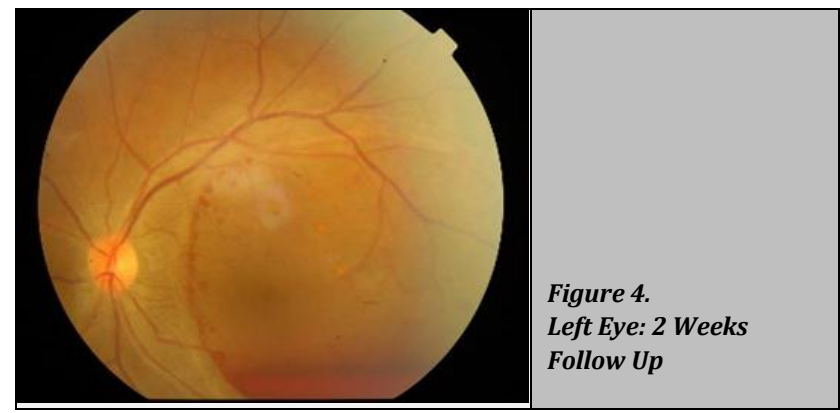

\section{DISCUSSION}

Severe retinopathy most commonly occur in HbS disease, however retinopathy is also not always absent in other types of sickle cell disease like $\mathrm{HbC}$, sickle cell trait (AS) and sickle cell thalassaemia (S-thal).

The incidence of sickle cell retinopathy has increased significantly due to increased physical quality of life index and its associated sequelae have also increased.[4]

Sickle cell trait is the least common to occur amongst all the sickle haemoglobinopathies, so retinopathy related to sickle cell trait is also rare to occur. Although $10 \%$ of sickle cell trait suffer from sickle cell retinopathy (SCR).[1]

Lieb et al[ ${ }^{[5]}$ in 1959 stated that patients with sickle cell trait had minimal or no fundal changes at all, but over the time AS cases have been found to develop sickle cell retinopathy both severe and non-severe kind.

This patient was diagnosed to have sickle cell trait 6 years ago when she had easy fatiguability and repeated episodes of loss of consciousness. Since then, patient has received multiple blood transfusions. This was the first time that patient has had ophthalmological complaints during her hospital stay or otherwise.

In a study conducted by Pareek, et al,[6] there was no significant correlation between the age and the gender of the patient as far as the ophthalmological findings are considered. There was no significant correlation between the duration of clinical features and the ophthalmological findings as well.

Male gender, patients in pain crises and splenic sequestration should be considered for a nearly ophthalmological examination whether or not symptoms are present since some studies prove their strong predisposition in sickle cell retinopathy.[1]

SCR can be classified as proliferative and non-proliferative retinopathy. Goldberg classifies proliferative disease into 5 grades.[1] Studies have documented up to $54.6 \%$ of SC patients 
and $18.1 \%$ of Homozygous sickle cell anaemia (SS) patients developing Grade 3-5 proliferative sickle cell retinopathies. Sickle cell retinopathy shows both anterior segment as well as posterior segment signs. Anterior segment findings include comma shaped conjunctival vessels, atrophic patches in iris, raised intraocular pressure, hyphaema may also be present.

Goldberg investigated a case of sickle cell trait presenting with raised IOP following hyphaema finding the sickled red blood cells are more concentrated in aqueous than in venous blood.

H. Jackson et al[7] concluded in his study that sickle cell retinopathy does occur in sickle cell trait but mostly it is associated with either raised IOP and/or following trauma or traumatic hyphaema. He also proposed that if the retinopathy exists without raised IOP and/or following trauma possibility of other comorbid conditions like diabetes and hypertension should be suspected.

Nagpal et al[1] conducted a study on 7 patients of sickle cell trait who had proliferative retinal disease but the nearly all the patients had co-existing comorbid associations like diabetes mellitus, hypertension, sarcoidosis, tuberculosis etc.

Kabakow $\mathrm{B}$ et $\mathrm{al}^{[8]}$ have showed that central retinal artery occlusion is a common occurrence along with sickle cell retinopathy in the patients with sickle cell trait.

Michelson PE et al[9] have also shown that central retinal artery occlusion is common following trauma in patients with sickle cell trait.

Retinal neoangiogenesis in a sea-fan configuration is the pathognomonic of PSR occurring in the junction of perfused and nonperfused retina, suggestive of proliferative disease. Sea-fans may spontaneously involute, resulting in areas of grayish white fibrovascular tissues that often have residual perfused retinal vessels at their base. About $40-50 \%$ may undergo some degree of auto infarction during their course. SCD patients should be started being screened early from the time of diagnosis to timely identify retinal lesions, visual and prevent the progression of NPSCR to severe retinopathy. Serial examinations may be done twice a year for eyes with normal findings in order to decrease morbidity. SCD patients with retinopathy suspicion or predisposed to develop SCR should undergo complete ophthalmologic examination and be followed up as necessary. The mainstay of primary prevention should consist in reducing the prevalence of SCD by controlling the spread and perpetuation of the $\mathrm{HbS}$ gene pool. This can only be done by efforts at pre-marital Mendelian counselling. The course for patients who have sickle hemoglobinopathies and associated ophthalmic disease is variable. If left untreated, the incidence of blindness from PSR is about $12 \%{ }^{[10]}$ Advancements in awareness, early screening and diagnosis and systemic therapy as well as modern day laser and vitrectomy techniques have greatly reduced the risk of vision loss.

\section{CONCLUSIONS}

Sickle cell retinopathy both proliferative and non-proliferative can occur in patients with sickle cell trait. Other co-existent disease is not necessary for occurrence of non-proliferative disease unlike the proliferative sickle cell retinopathy for which existence of other comorbid conditions is a common occurrence. Treatment modality of non-proliferative disease mainly includes observation and frequent follow ups. Intra ocular pressure and anterior segment should be thoroughly examined. So that proliferative disease leading to retinal detachment and irreversible blindness may be prevented.

\section{REFERENCES}

[1] Nagpal KC, Asdourian GK, Patrianakos D, et al. Proliferative retinopathy in sickle cell trait. Report of seven cases. Arch Intern Med 1977;137(3):325-8.

[2] Lehmann H, Cutbush M. Sickle-cell trait in Southern India. Br Med J 1952;1(4755):404-5.

[3] Colah R, Mukherjee M, Ghosh K. Sickle cell disease in India. Curr Opin Hematol 2014;21(3):215-23.

[4] Verghese B, Acharya S, Khandekar A, et al. Clinical profile of patients of sickle cell crisis in a rural tertiary care hospital. J Evolution Med Dent Sci 2019;8(42):3114-8.

[5] Lieb WA, Geeraets WJ, Guerry D. Sickle cell retinopathy: Ocular and systemic manifestations of sickle cell disease. Acta Ophthalmol (Copenh) 1959;58:3-45.

[6] Pareek A, Khandekar A, Acharya S, et al. Correlation between nephropathy and ophthalmic complications in cases of sickle cell anemia: an entangled association. Indian J Med Spec 2019;10(2):72-5.

[7] Jackson H, Bentley CR, Hingorani M, et al. Sickle retinopathy in patients with sickle trait. Eye (Lond) 1995;9(Pt 5):589-93.

[8] Kabakow B, Van Weimokly SS, Lyons HA. Bilateral central retinal artery occlusion. AMA Arch Ophthalmol 1955;54(5):670-6.

[9] Michelson PE, Pfaffenbach D. Retinal arterial occlusion following trauma in youths with sickle trait hemoglobinopathy. Am J Ophthalmol 1972;74(3):494-7.

[10] Mehta JS, Whittaker KW, Tsaloumas MD. Latent proliferative sickle cell retinopathy in sickle cell trait. Acta Ophthalmological Scandinavica 2001;79(1):81-2. 